\title{
A Case of Pregnant Female Detected with Ampullary Carcinoma, the Course of the Disease and Pregnancy after Pancreaticoduodenectomy (Whipple's Procedure)
}

\author{
Nisma M. Al Mansouri, MBChB, ABOG \\ Department of Obstetrics and Gynecology, Faculty of Medicine \\ King Abdulaziz University \\ Jeddah, Saudi Arabia
}

\section{Correspondence}

Dr. Nisma M. Al Mansouri

P.O. Box 80215, Jeddah 21589, Saudi Arabia

e.M:drnismansouri@hotmail.com

Submission: 14 Aug. 2016

Accepted: $\quad 30$ Aug. 2016

\section{Citation}

Al Mansouri NM. A case of pregnant female detected with ampullary carcinoma, the course of the disease and pregnancy after pancreaticoduodenectomy (Whipple's Procedure). JKAU Med Sci 2016; 23 (4): 43-48. DOI: 10.4197/Med. 23.4.5

\begin{abstract}
Ampullary and pancreatic carcinoma have high mortality rates particularly among the solid tumors. The median survival of untreated metastatic and locally advanced ampullary and pancreatic carcinoma are 3-5 and 6-10 months, respectively. The worldwide mortality due to these types of malignancies is increasing with more reported cases from the Middle East and North Africa. The incidence of ampullary carcinoma among pregnant females is rare. A limited number of cases have been reported. Here we report a case of a pregnant female detected with ampullary carcinoma, the course of the disease and pregnancy after pancreaticoduodenectomy (Whipple's procedure).
\end{abstract}

\section{Keywords \\ Pregnancy; Ampullary and pancreatic carcinoma; Whipple's procedure}

\section{Introduction}

A mpullary and pancreatic carcinoma have high mortality rates particularly among the solid tumors $^{[1-3]}$. The median survival of untreated metastatic and locally advanced ampullary and pancreatic carcinoma are 3-5 and 6-10 months respectively ${ }^{[4]}$. The worldwide mortality due to these types of malignancies is increasing with more reported cases from the Middle East and North Africa ${ }^{[5]}$.

The incidence of ampullary carcinoma among pregnant females is rare $^{[6]}$. A limited number of cases have been reported. Here we report a case of a pregnant female detected with ampullary carcinoma, the course of the disease and pregnancy after pancreaticoduodenectomy (Whipple's procedure).

\section{Case Report}

A 40 years old woman presented in July 2014 at 28 weeks into her pregnancy with abdominal pain, pruritus and jaundice. She had eight earlier pregnancies (G9 P8+0) and the above symptoms started three months prior to her presentation as right upper abdominal pain followed shortly afterwards with pruritus and later jaundice. She had a history of pre-eclampsia and also had an episode of pulmonary embolism (PE) during one of her pregnancies, following which she was confirmed with protein $\mathrm{S}$ deficiency. She had delivered 
all babies in the past at full term and through normal vaginal delivery. She had one intrauterine fetal death (IUFD). She was a known case of protein $S$ deficiency and had history. The liver function tests were abnormal with elevation of the total bilirubin to $152 \mathrm{umol} / \mathrm{L}$ (017), mainly direct hyperbilirubinemia ( $131 \mathrm{umol} / \mathrm{L}$ ). The alkaline phosphatase (ALP) was raised at $597 \mathrm{U} / \mathrm{L}$ and she had markedly low albumin at $17 \mathrm{~g} / \mathrm{L}$. Both alanine trasaminase (ALT) and aspartate transferase were within the normal range.

Abdominal ultrasonography demonstrated dilatation of the common bile duct, cystic ducta along with dilatation of both the intra and extrahepatic bile ducts. The findings were confirmed by an MRI/MRCP examination. She therefore had endoscopic retrograde cholangio-pancreatography (ERCP) under conscious sedation. The attempted cannulation of the papilla was unfortunately unsuccessful and so the biliary drainage could not be achieved. The endoscopic examination did however reveal the presence of a tumor around the ampulla which was biopsied and confirmed to be periampullary adenocarcinoma. The histopathology examination described three superficial fragments of intestinal mucosa with highly dysplastic glands. These glands exhibited high N/C ratio, hyperchromasia, and pleomorphism. There was no evidence of invasion or desmoplasia.

In view of the significant biliary obstruction, the patient underwent percutaneous transhepatic cholangiography (PTC) and insertion of internal/ external drainages of the biliary system. Her symptoms improved and the liver functions showed return of normality to the bilirubin, GGT and ALP (Table 1). No further intervention was attempted and the decision for surgery was deferred until after the delivery. She had uneventful spontaneous vaginal delivery and the only complication was a stitch, resolved on conservative management.

Post-delivery, she had a CT scan of the abdomen which confirmed the presence of the peri-ampullary

Table 1. Liver function test post biliary drainage.

\begin{tabular}{|l|c|}
\hline Total Protein & $48 \mathrm{~g} / \mathrm{L}$ \\
\hline Albumin & $21 \mathrm{~g} / \mathrm{L}$ \\
\hline Alkaline Phosphatase & $77 \mathrm{U} / \mathrm{L}$ \\
\hline Aspartate Amino Transferase & $35 \mathrm{U} / \mathrm{L}$ \\
\hline Alanine Amino Transferase & $21 \mathrm{U} / \mathrm{L}$ \\
\hline Bilirubin -Total & $10 \mathrm{umol} / \mathrm{L}$ \\
\hline Gamma-Glutamyl Transferase & $42 \mathrm{U} / \mathrm{L}$ \\
\hline
\end{tabular}

tumor with no evidence of distant metastases (Figs 1 and 2). The bone scan excluded any bony metastases and on 28th October 2014 she underwent pancreaticoduodenectomy (Whipple's procedure). Hematoma formation occurred following surgery which resolved spontaneously. She did not receive any chemotherapy post-surgery and her follow up CT scan was satisfactory with no evidence of recurrence (Fig. 3).

The patient became pregnant four months after Whipple surgery. She had an admission early in the pregnancy with one episode of vomiting that lasted 3 days accompanied by dull epigastric pain. The clinical examination was unremarkable and so was the laboratory investigation. The albumin was slight below the normal range at $34 \mathrm{~g} / \mathrm{L}$, however the ALT, ALP, GGT and bilirubin were all within the normal range. The rest of the pregnancy period was uneventful and she delivered a full-term baby on $2^{\text {nd }}$ November, 2015.

The latest clinic assessment was in April 2016. She was clinically well with unremarkable abdominal examination. The laboratory test demonstrated normality of the liver function tests (LFTs), full blood count and renal function (Table 2). The follow-up CT on

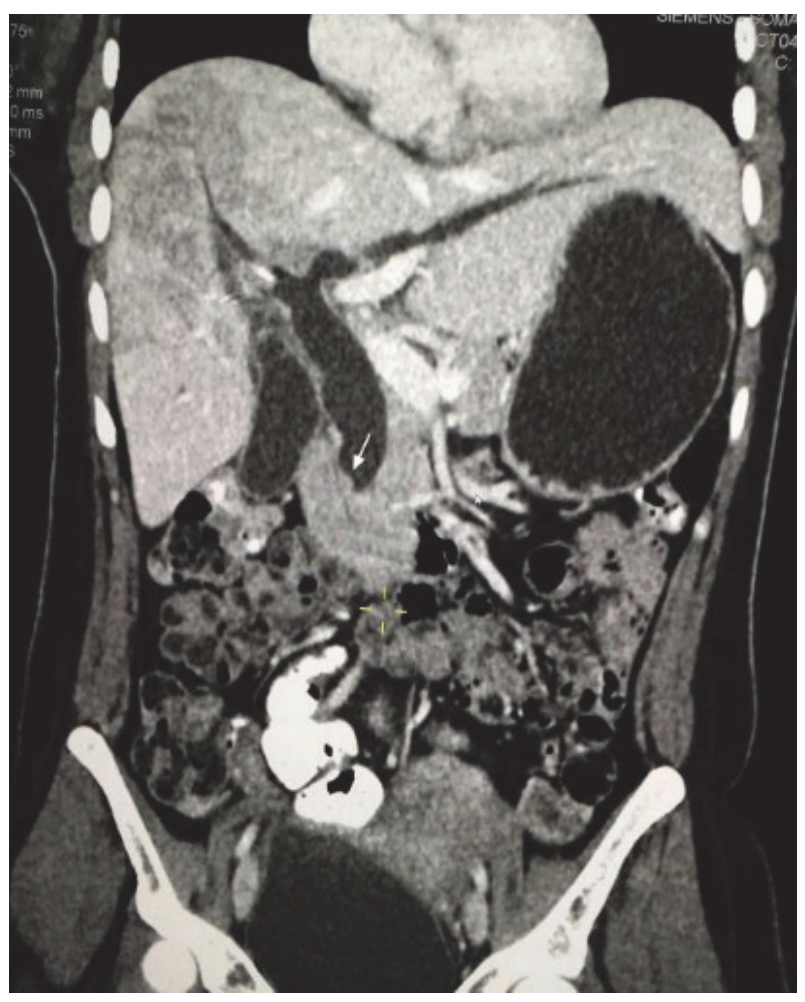

Figure 1. Marked distended common bile duct with abrupt cut off of distal end (see white arrow) with secondary dilation of intra-hepatic biliary radical. Pre-Operative CT scan. 
A Case of Pregnant Female Detected with Ampullary Carcinoma, the Course of the Disease and Pregnancy...

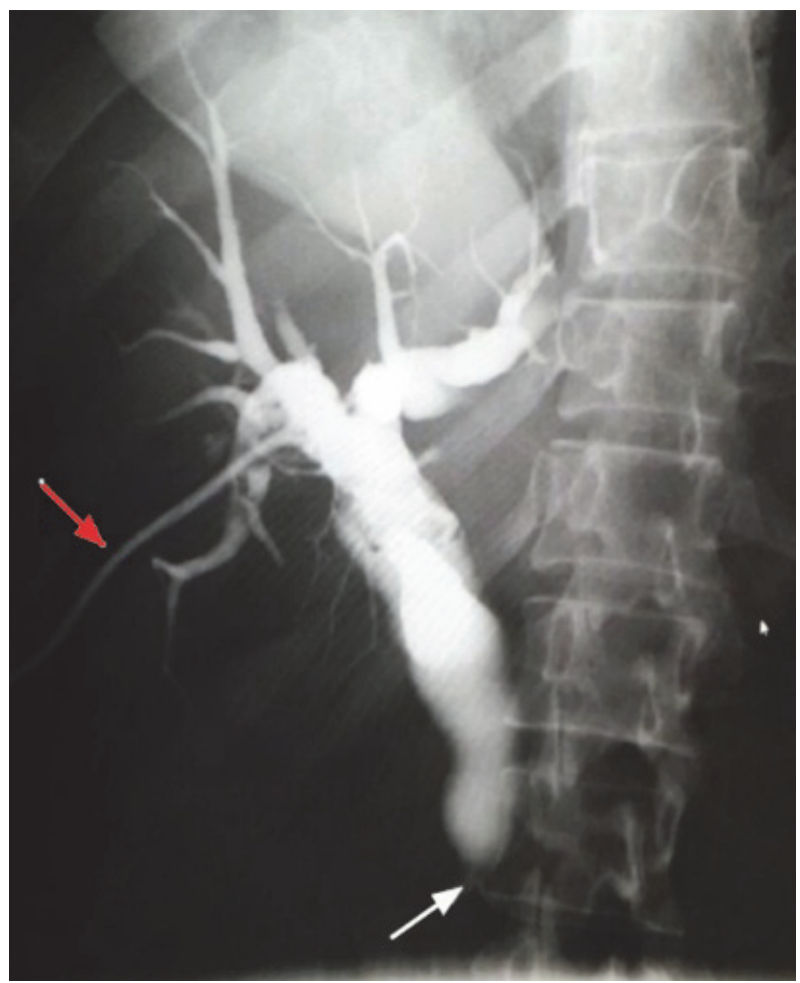

Figure 2. Marked distended common bile duct with abrupt cut off of distal end (see white arrow) with secondary dilation of intra-hepatic biliary radical (red arrow is percutaneous transhepatic cholangiography tube). Pre-operative ERCP.

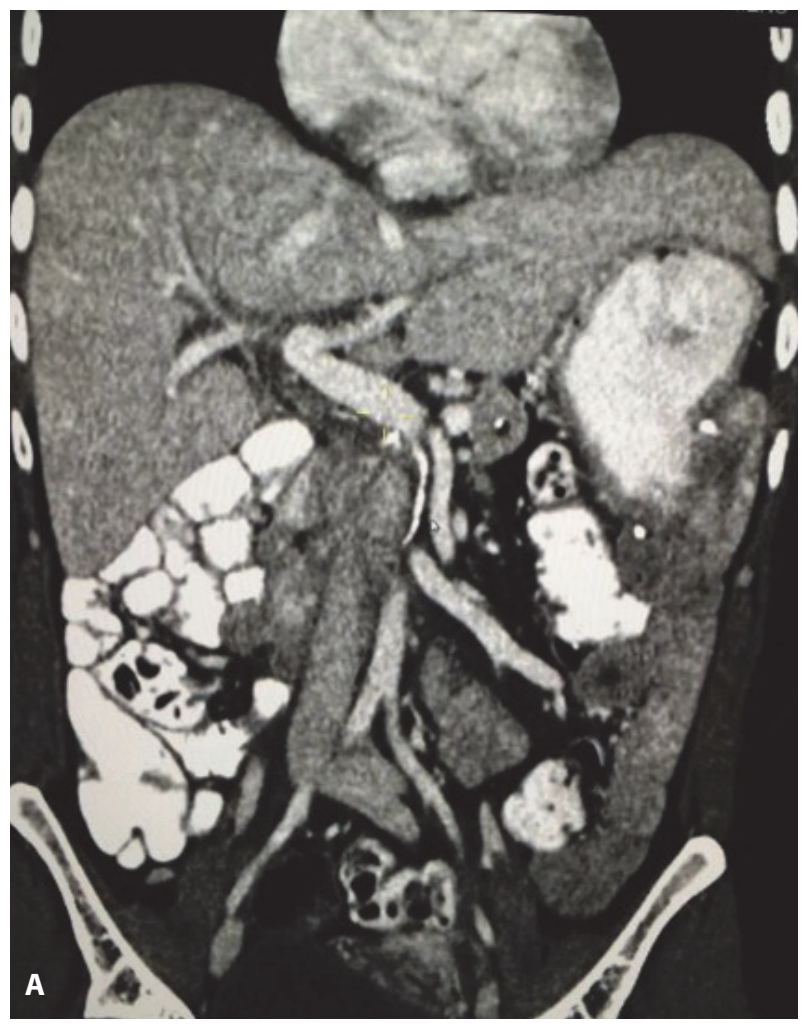

Table 2. Follow up LFTS (18 months post Whipple).

\begin{tabular}{|l|c|}
\hline Total Protein & $48 \mathrm{~g} / \mathrm{L}$ \\
\hline Albumin & $37 \mathrm{~g} / \mathrm{L}$ \\
\hline Alkaline Phosphatase & $103 \mathrm{U} / \mathrm{L}$ \\
\hline Aspartate Amino Transferase & $25 \mathrm{U} / \mathrm{L}$ \\
\hline Alanine Amino Transferase & $33 \mathrm{U} / \mathrm{L}$ \\
\hline Bilirubin -Total & $4 \mathrm{umol} / \mathrm{L}$ \\
\hline Gamma-glutamyl Transferase & $40 \mathrm{UI} / \mathrm{L}$ \\
\hline
\end{tabular}

Abbrv: LFTS = Liver function tests

$17^{\text {th }}$ April, 2016 did not show any recurrence and the only reported abnormality was an interval decrease in the size of the uterus.

\section{Discussion}

We described a case of ampullary carcinoma in a 40 year old pregnant female and outlined the course of management during the pregnancy and also reported the outcome after she underwent Whipple's procedure in the postpartum period. The risk/benefit balance in her case weighed in favor of deferring the surgical resection until after the delivery of the baby and therefore she underwent biliary drainage to alleviate the obstruction. In absence of local or distal metastases, Whipple's procedure provides the best survival outcome for patients with ampullary or pancreatic carcinoma ${ }^{[7]}$.

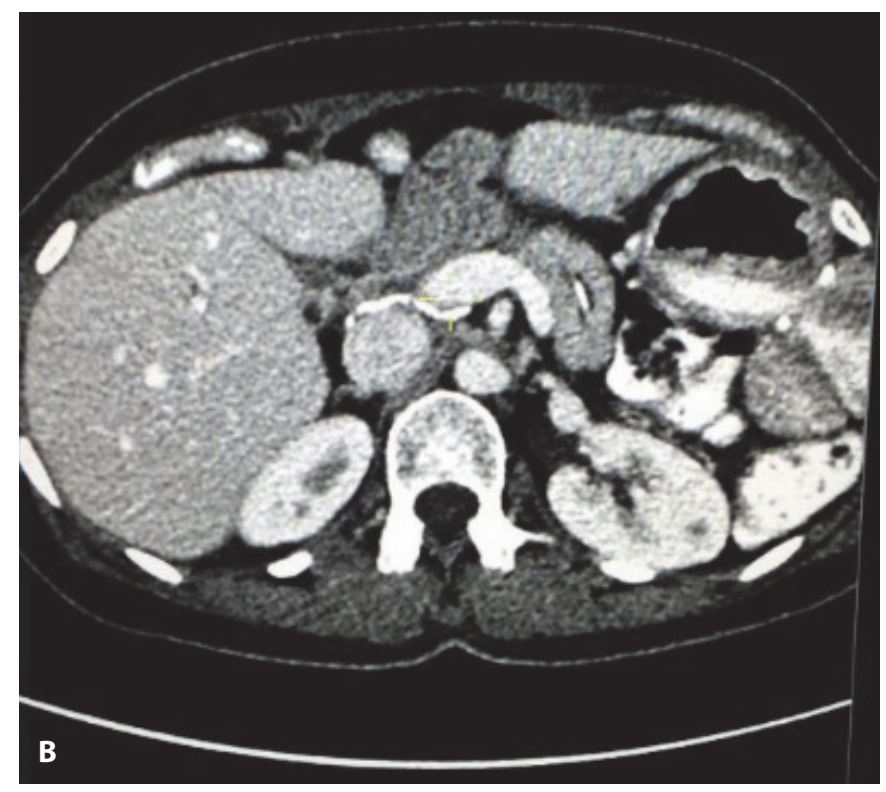

Figure 3. Post Whipple procedure CT scan (after 18 months). (A) Coronal view; (B) Axial view. 
Ampullary and pancreatic malignancies are rare in this age group with a limited number of case reports during pregnancy ${ }^{[6,8,9]}$. We systematically searched the literature with the keywords (((pregnancy) OR "Pregnancy"[Mesh])) AND ((pancreatic adenocarcinoma) OR ("Carcinoma, Pancreatic Ductal"[Mesh]) OR ampullary carcinoma)), for case reports or series or clinical studies and epidemiological data on the incidence and management strategies among patients with ampullary carcinoma among pregnant females. Initial search identified 123 articles and we further limited to case reports or clinical studies published till now. We didn't apply any restriction of time and language. There are isolated case reports from across the world.

The limited number of case reports of ampullary and pancreatic cancer among pregnant females have all highlighted the diagnostic challenges particularly with the symptoms that may not differ from those encountered during pregnancy ${ }^{[10-12]}$. Peer review reported cases of surgery for pancreatic cancer during pregnancy whereby all mothers except one delivered live term babies ${ }^{[13]}$. A case report by Boyd et al. ${ }^{[14]}$ described the outcome in a 30 year old pregnant female with ampullary carcinoma and a large left ovarian cystadenoma. It was an advanced malignancy that caused duodenal obstruction. She underwent resection of the ovarian tumor and the management of the periampullary malignancy was limited to palliative gastrojejunostomy ${ }^{[14]}$. Various case reports described successful outcome after pancreaticoduodenectomy in pregnant females with pancreatic or ampullary adenocarcinoma ${ }^{[15-19]}$. However, there are reports of poor outcome of patients who died within a year from the diagnosis. Marinoni et al. ${ }^{[6]}$ reported a case of a young pregnant patient diagnosed with pancreatic cancer at 28 weeks of pregnancy. The tumour metastasized to the liver and the lungs. The baby was delivered by caesarean at 30 weeks and the patients died unfortunately within 2 months from the delivery ${ }^{[6]}$. Lubner et al. ${ }^{[20]}$ have described a pregnant female (37 years old), who was diagnosed with periampullary carcinoma after 16 weeks of gestation. As she had grade 3 adenocarcinoma, she underwent pancreaticoduodenectomy and adjuvant gemcitabine therapy post-surgery. She delivered at 35 months; however, she died 12 months after diagnosis ${ }^{[20]}$.

The role of the female sex hormones in pancreatic and ampullary adenocarcinoma has been explored ${ }^{[21,22]}$. Duffield et al. ${ }^{[22]}$ have reported two cases of pregnant females with retroperitoneal masses and increased levels of human chorionic gonadotropin (hCG). One patient had epidermoid cyst and the other had pancreatic ductal adenocarcinoma. Levels of hCG paralleled the secretion of cancer antigen 19-9 in the patient with adenocarcinoma and it reflected the course of disease progression ${ }^{[22]}$. Madu et al. ${ }^{[23]}$ suggested that pancreatic and ampullary tumors may grow faster during pregnancy due to the influence of the female sex hormones and have advocated early surgical intervention for better prognosis ${ }^{[23]}$.

Although incidence of pancreatic and ampullary cancer is rare during pregnancy, it is critical to suspect in case of epigastric pain and symptoms of biliary obstruction. Our case was diagnosed with pancreatic adenocarcinoma in the early stages, which helped in achieving a good prognosis. Approximately $80 \%$ of the patients have locally advanced or metastatic pancreatic carcinoma at the time of diagnosis ${ }^{[1]}$. One of the important reasons of poor prognosis and increased mortality includes late diagnosis ${ }^{[4]}$. Our patient didn't have any of the known risk factors for occurrence of ampullary cancer. None of the risk factors like gender, age, smoking and alcohol status, obesity and/or diabetes were present in our patient ${ }^{[7]}$.

One very important feature of this case is that the patient got pregnant after pancreaticoduodenectomy and later delivered a healthy baby at term. Madu et al. ${ }^{[23]}$ have also described a case who got pregnant $<2$ weeks after pancreaticoduodenectomy for pancreatic cancer. As with our patient, complete resection of the tumor in the absence of local or distant metastases results in good prognosis. Equally, there does not appear to be a significant impact on the nutrition status of the patient post Whipple's procedure and it appears to be safe to consider pregnancy in this group of patients.

\section{Conclusions}

The above case adds to our understanding on the presentation and outcome of this rare malignancy during pregnancy. Given the nature of the symptoms that mimic those related to pregnancy, a high index of suspicion is needed for early diagnosis and better outcome. Decision regarding the timing of surgery and need of chemotherapy is to be individualized.

\section{Conflict of Interest}

The author has no conflict of interest. 
A Case of Pregnant Female Detected with Ampullary Carcinoma, the Course of the Disease and Pregnancy... N.M. AlMansouri

\section{Disclosure}

The author did not receive any type of commercial support either in forms of compensation or financial for this study. The author has no financial interest in any of the products or devices, or drugs mentioned in this article.

\section{Ethical Approval}

Obtained.

\section{References}

[1] Zhang Q, Zeng L, Chen Y, Lian G, Qian C, Chen S, Li J, Huang K. Pancreatic cancer epidemiology, detection, and management. Gastroenterol Res Pract 2016; 2016: 8962321.

[2] Panzeri F, Crippa S, Castelli P, Aleotti F, Pucci A, Partelli S, Zamboni G, Falconi M. Management of ampullary neoplasms: A tailored approach between endoscopy and surgery. World J Gastroenterol 2015; 21(26): 7970-7987.

[3] Hurton SM, Hayden JA, Molinari M. Adjuvant therapy for resected pancreatic cancer. In: Cochrane Database of Systematic Reviews. Chichester, UK: John Wiley \& Sons, Ltd, 2015.

[4] Halfdanarson TR, Haraldsdottir S, Borad MJ. Advances in systemic therapy for advanced pancreatobiliary malignancies. F1000Res 2013; 2: 105.

[5] [No authors listed]. GLOBOCAN 2012: Estimated cancer incidence, mortality and prevlence worldwide in 2012. Accessed 2016 from: <http://globocan.iarc.fr/Pages/fact_ sheets_population.aspx>.

[6] Marinoni E, Di Netta T, Caramanico L, Tomei B, Moscarini M, Di lorio R. Metastatic pancreatic cancer in late pregnancy: A case report and review of the literature. J Matern Fetal Neonatal Med. 2006; 19(4): 247-249.

[7] Kamisawa T, Wood LD, Itoi T, Takaori K. Pancreatic cancer. Lancet 2016; 388(10039): 73-85.

[8] Perera D, Kandavar R, Palacios E. Pancreatic adenocarcinoma presenting as acute pancreatitis during pregnancy: clinical and radiologic manifestations. J La State Med Soc 2011; 163(2): 114-147.

[9] Boyd CA, Benarroch-Gampel J, Kilic G, Kruse EJ, Weber SM, Riall TS. Pancreatic neoplasms in pregnancy: diagnosis, complications, and management. J Gastrointest Surg 2012; 16(5): 1064-1071.

[10] Boyle JM, McLeod ME. Pancreatic cancer presenting as pancreatitis of pregnancy. Case report. Am J Gastroenterol 1978; 70(4): 371-373.

[11] Farah F, Mlika M, Eddiba T, Zermani R, Jilani SBB. Undifferentiated carcinoma with osteoclast-like giant cells of the pancreas (A Case Report). Pancreatic Disorders Ther Open Access 2012; 1(2): 1-4.
[12] Qiao PF, Niu GM, Gao Y. Misdiagnosis of pancreatic papillary mucinous cystadenocarcinoma: A case report. Oncol Lett 2014; 8 (3): 1070-1074.

[13] [No authors listed]. Peer review report 2 on "Pancreatic mucinous cystadenocarcinoma: Epidemiology and outcomes". Int J Surg 2017; Suppl 1: S79.

[14] Boyd CA, Benarroch-Gampel J, Sheffield KM, Cooksley CD, Riall TS. 415 patients with adenosquamous carcinoma of the pancreas: a population-based analysis of prognosis and survival. J Surg Res 2012; 174(1): 12-19.

[15] Blackbourne LH, Jones RS, Catalano CJ, lezzoni JC, Bourgeois FJ. Pancreatic adenocarcinoma in the pregnant patient: case report and review of the literature. Cancer 1997; 79(9): 1776-1779.

[16] Shirakawa S, Matsumoto I, Nakayama S, Mukubo H, Toyama H, Shinzeki M, Fukumoto T, Ajiki T, Ku Y. [Mucinous cystic neoplasm of the pancreas associated with pregnancy: report of two cases]. Nihon Shokakibyo Gakkai Zasshi 2010; 107(11): 1828-1834.

[17] Boumans D, Weerink LB, Rheineck Leyssius AT, Swartbol $P$, Veneman TF. Splenic artery rupture during pregnancy concealed by a pancreatic lymphangioma: a rare cooccurrence. Ann Vasc Surg 2013; 27(1): 112.e1-4.

[18] lida T, Nakabayashi Y, Okui N, Shiba H, Otsuka M, Yanaga K. Successful management of metachronous liver metastasis after pancreaticoduodectomy for pancreatic ductal carcinoma using hepatectomy and chemotherapy: a case report. Anticancer Res 2014; 34(5): 2417-2420.

[19] Lee E, Horn-Ross PL, Rull RP, Neuhausen SL, Anton-Culver H, Ursin G, Henderson KD, Bernstein L. Reproductive factors, exogenous hormones, and pancreatic cancer risk in the CTS. Am

[20] Lubner S, Hall B, Gopal D, Soni A, Hegeman R, Winterle N, Loeffler A, Weber S, Reeder S, Locante N. A 37-yearold pregnant woman with pancreatic adeno-carcinoma treated with surgery and adjuvant chemotherapy: A case report and literature review. J Epidemiol 2013; 178(9): 1403-1413.

[21] Dray D, Dahlke JD, Rouse DJ. Recurrent pancreatitis in pregnancy after preconception Whipple for pseudopapillary pancreatic tumor. Obstet Gynecol 2014; 124 (2 Pt 2 Suppl 1): 469-471

[22] Duffield AS, Jarrar P, Shum C, Ahuja N, Yeo CJ, Sokoll LJ. Retroperitoneal masses with associated human chorionic gonadotropin production: Report of two cases. Clin Chim Acta 2008; 395(1-2): 166-169.

[23] Madu AE, Osoba O. Pregnancy following Whipple's procedure. J Obstet Gynaecol 2007; 27(8): 855-857. 


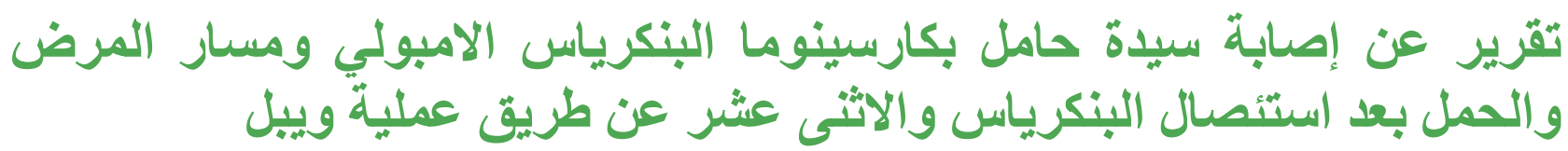

$$
\begin{aligned}
& \text { نسمة محمد المنصوري } \\
& \text { قسم النساء و الولادة، كلية الطب ولئب والعلوم الطبية، } \\
& \text { جامعة الملك عبد العزبيز } \\
& \text { جلة ـ المملكة العربية السعودية العين }
\end{aligned}
$$

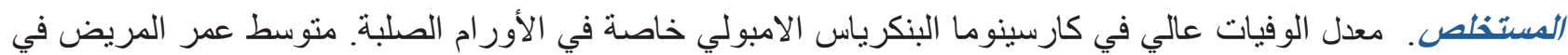

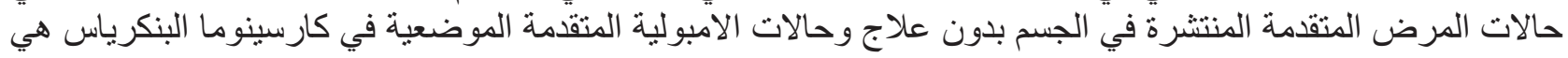

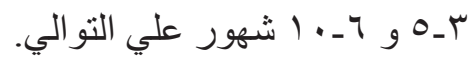
معدل الوفيات حول العالم بسبب هذه السرب السرطانات في زيادة مع تسجيل حالات أكثر في منطقة الشرق الأوسط وشمال إفريقيا.

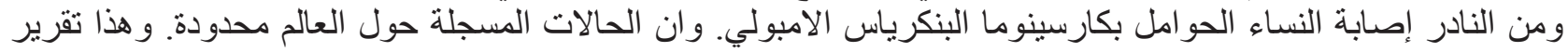

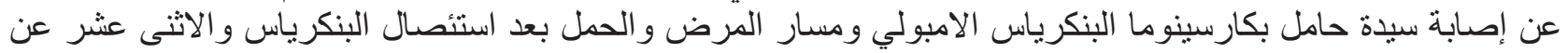
طريق عملية ويبل. 